\title{
Life cycle assessment of greenhouse gas emissions arising from the production of glued and pressed wall panels derived from Guadua Angustifolia Kunth (bamboo) in Ecuador
}

\author{
A. D. Ramirez, D. Torres, P. Peña \& J. Duque-Rivera \\ Escuela Superior Politécnica del Litoral (ESPOL), Ecuador
}

\begin{abstract}
Traditionally in coastal Ecuador, Guadua Angustifolia Kunth (GAK), a bamboo cane, has been used as a wall material. Typically, the GAK cane is opened and used almost directly without any preservation as wall material in underprivileged areas. A local entrepreneur is developing glued and pressed panels derived from GAK. It is claimed that the GAK glued and pressed panels (GAKGPP) last for 40 years, while traditional GAK walls last for 5 years. Life cycle assessment (LCA) is a quantitative environmental assessment tool that has been used to assess all type of products and services. LCA can also be used as a methodological framework to quantify emissions affecting Climate Change, the result from such an LCA is commonly known as Carbon Footprint (CF). The CF associated with the production of the GAKGPP has been calculated using a life cycle approach with the objective of determining the main contributors to the $\mathrm{CF}$ and analyzing the climate benefits of using GAKGPP in comparison to the traditional GAK panels. The main study has a cradle-to-gate approach; phases included in the product system are: agriculture, production of inputs, transportation of main inputs and GAK canes, and panels manufacturing. Durability during the use phase is included only to perform the comparison. Data to quantify product flows have been compiled from a GAK farm, a panel manufacturing plant, literature and databases. Data to quantify GHG emissions have been calculated using guidelines, literature, and/or derived from databases. The main contributors to the CF of the GAKGPP are the production of the glue chemicals and the transport of the GAK canes from the farm to the manufacturing plant. It is found that the durability of
\end{abstract}


the GAKGPP during the use phase is a fundamental aspect to assure climate benefits when compared to traditional panels.

Keywords: carbon footprint, LCA, bamboo, GHG, climate change, wood, durability.

\section{Introduction}

In Latin America, there are approximately 30 species of Guadua, a bamboo cane that grows in almost all countries. Of those, Guadua Angustifolia Kunth (GAK) is an adequate material to be used as structural or wall materials in buildings due to its physical and mechanical properties. GAK canes can reach 30 meters high [1]. It is estimated that in Ecuador, there is 9270 ha cultivated with several species of bamboo, 4270 of human made plantations and 5000 ha of natural plantations, however only 3500 ha are economically usable [2].

In Ecuador, GAK is normally used as building material for housing in underprivileged areas. Normally the GAK cane is simply opened and used almost directly as a wall material. A local entrepreneur is developing glued and pressed panels using GAK canes. The GAK glued and pressed panels (GAKGPP) are more durable than traditional GAK panels.

Environmental friendliness is an attribute that nowadays has become desirable in every sector. The housing and building sector is not the exception. There is a wide range of tools that can be used to assess sustainability [3]. Life Cycle Assessment (LCA) is the most established tool to assess the environmental burden of a product or service along its life cycle. LCA has been used successfully to evaluate the environmental or energy performance of both entire buildings and construction materials $[4,5]$. The LCA methodological framework is standardized by ISO $[6,7]$.

Climate change is perceived as one the main challenges to sustainability that humankind faces nowadays. LCA can also be used as a tool to evaluate the Greenhouse Gas (GHG) emissions from product systems. The result of an LCA dedicated to assess GHG emissions only is commonly known as Carbon Footprint (CF). This approach towards LCA is standardized by BSI [8].

LCA has been used to analyze the environmental burden of bamboo as building material from Costa Rica and China [9, 10], and bamboo derived housing in China [11]. Depending on agricultural and manufacturing practices, and methodological approaches LCA can provide different results. There are no publicly available studies that evaluate the environmental friendliness of Ecuadorian GAK panels (neither traditional nor glued and pressed panels). The objectives of this study are: (i) to calculate the carbon footprint associated with GAKGPP, and (ii) to compare it with that of the traditional GAK panel.

\section{Methodology}

This study was prepared using the guidelines to develop GHG LCA of goods and services as prescribed by BSI $[8,12]$. The first step includes the definition of the scope of the study, which mostly involves the definition of the functional unit and 
the system boundaries of product system to be analysed. The second step involves the collection of data. There is two types of data to be collected, the activity data and the emission factors. Activity data includes the quantities of inputs and outputs of the system. Emission factors are values that are used to convert the activity data into GHG emissions. The third step involves the calculation of the life cycle GHG emissions for all the processes and the analysis of the contribution of each process. The final step is the interpretation of the results which involves finding the hotspots of the system and envisioning improvement measures.

\subsection{Scope}

The functional unit of the study is a GAKGPP of an area of $2.98 \mathrm{~m}^{2}(1.22 \mathrm{~m} \mathrm{x}$ $2.44 \mathrm{~m}$ ), with a mass of $41.91 \mathrm{~kg}$, to be used as wall material with a life span of between 20 and 30 years. Figure 1 illustrates one of these panels. The study has a cradle-to-gate approach, thus the life cycle phases included in the system are: agriculture, preservation, and manufacturing.

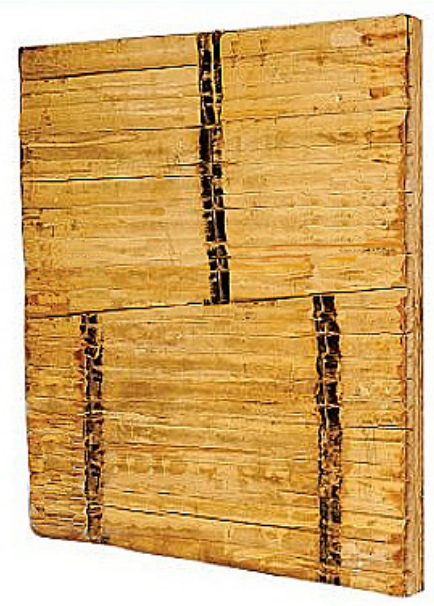

Figure 1: Guadua Angustifolia Kunth glued and pressed panels (GAKGPP)

The agriculture phase includes the production and maintenance of offsets, the production and use of agricultural inputs, and the maintenance of the plantation. The GAK plantation is located in Los Ríos province of Ecuador. The location is presented in Fig 2. A GAK plantation requires between 2 and 6 years until it is usable for production. In order to sustain the plantation, only $25 \%$ to $40 \%$ of the plantation can be extracted per year. GAK in Ecuador is commonly reproduced by propagation. This process includes extracting offsets from plantations, planting them in propagation banks, and finally planting mature offsets in the plantation site. Plastic bags are used to transport the offsets. Plantations require water, fertilisers and pest control products. Fertilisers used are urea, triple super phosphate, and potassium chloride. Glyphosate is used as pest control. 
Since GAK has internal humidity, it is vulnerable to fungus and other agents. Preservation and drying is required in order to prevent damages to its structure. GAK canes are left to dry at the plantation site for 4 weeks. After dried, GAK canes are immersed in a solution of immunization products. Immersion lasts for 5 days, after that, the GAK canes are dried naturally. Preservation is performed near the plantation, however transport is needed. Substances used are boric acid, boric oxide, and insecticide.

In the studied system, manufacturing of GAKGPP takes place in a city near Guayaquil in the Guayas province of Ecuador. Two GAK canes are needed to produce a panel. GAK canes are brought to the manufacturing plant where they are cleaned using steel sponges. Canes are opened and cut. The opened canes are glued and pressed for 30 minutes with a hydraulic press. After that, the GAKGPP are ready to be used. Location of the GAKGPP manufacturing is presented in Fig. 2.

The system boundaries used in this study are presented in Fig 3.

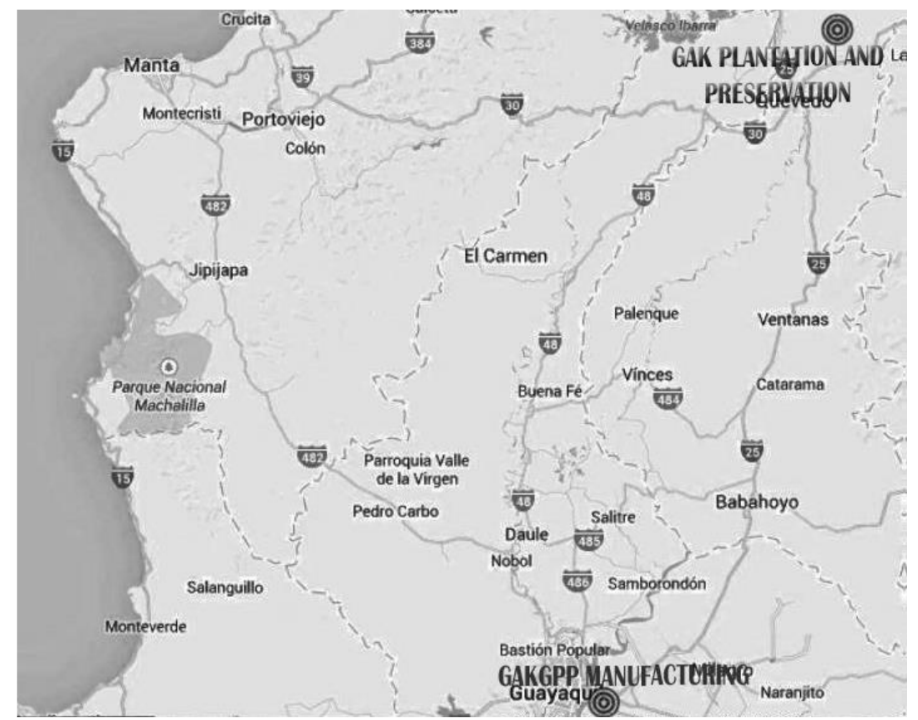

Figure 2: Location of the GAK plantation and preservation and the GAKGPP manufacturing plant

\subsection{Data and calculation}

Activity data is derived mostly from interviews with GAK plantation staff and GAKGPP manufacturing plant staff and from the literature. Distances are derived from Google maps [13]. Table 1 presents the quantities of inputs and outputs normalised for the functional unit. Emission factors for almost all the processes in Table 1 were derived from Ecoinvent databases [14]. Emission of $\mathrm{CO}_{2}$ and $\mathrm{N}_{2} \mathrm{O}$ derived from urea application were calculated using Tier 1 procedures from IPCC [15]. The $\mathrm{CO}_{2}$ emission associated with the production of electricity in Ecuador is derived from [16]. 


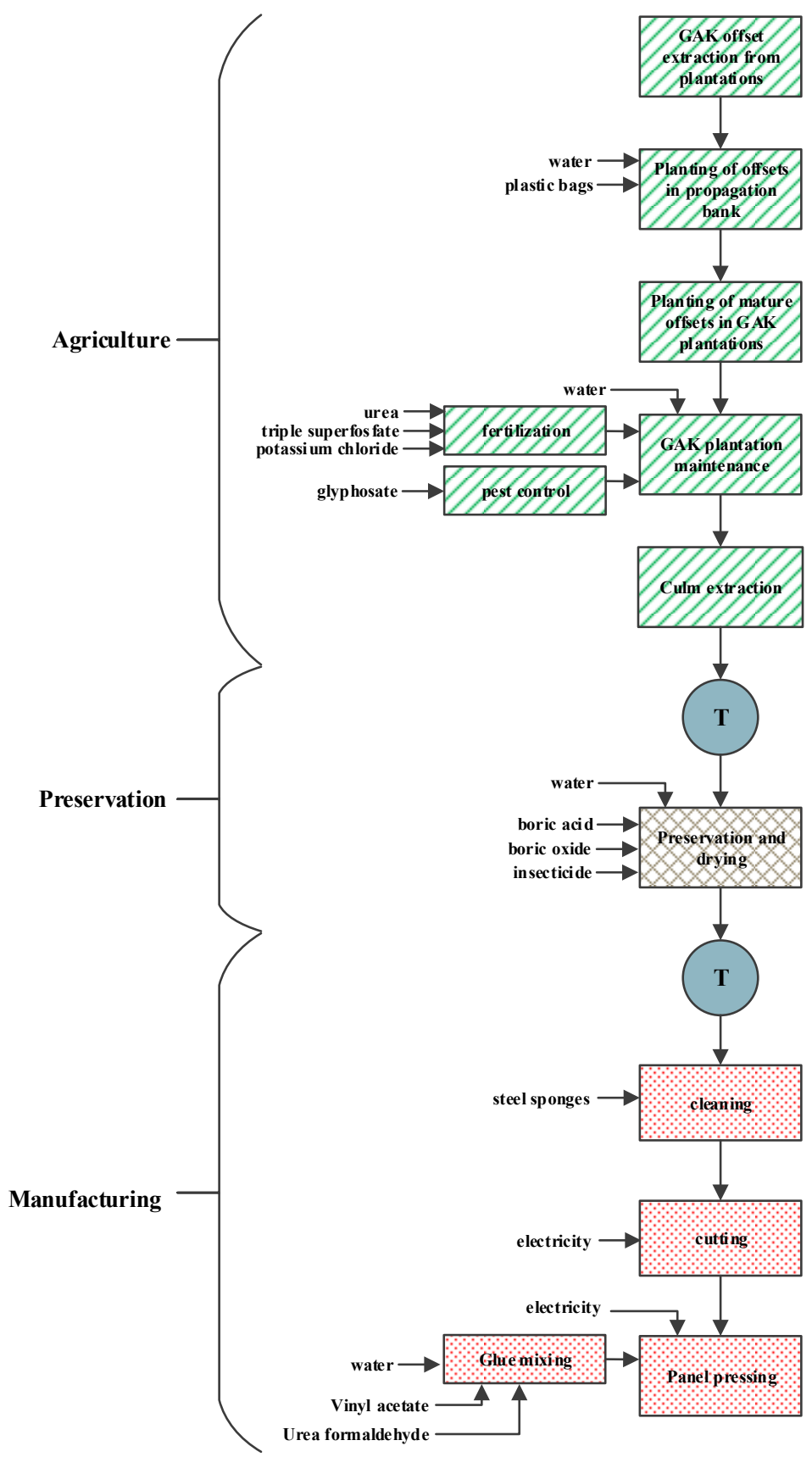

Figure 3: System boundaries. 
Table 1: Activity data normalised for the functional unit.

\begin{tabular}{|c|c|c|}
\hline Life cycle stage & Process & Quantity \\
\hline \multirow[t]{12}{*}{ Agriculture } & Water & $5,651 \mathrm{~kg}$ \\
\hline & Transport of water & $56,51 \mathrm{~kg}-\mathrm{km}$ \\
\hline & Plastic bags production & $0,005 \mathrm{~kg}$ \\
\hline & Transport of Plastic bags & $0,82 \mathrm{~kg}-\mathrm{km}$ \\
\hline & Urea production & $0,017 \mathrm{~kg}$ \\
\hline & Urea transport & $3,03 \mathrm{~kg}-\mathrm{km}$ \\
\hline & Triple super phosphate production & $0,008 \mathrm{~kg}$ \\
\hline & Transport of Triple super phosphate & $1,34 \mathrm{~kg}-\mathrm{km}$ \\
\hline & Potassium chloride production & $0,036 \mathrm{~kg}$ \\
\hline & Transport of Potassium chloride & $6,32 \mathrm{~kg}-\mathrm{km}$ \\
\hline & Glyphosate production & $0,002 \mathrm{~kg}$ \\
\hline & Transport of Glyphosate & $0,38 \mathrm{~kg}-\mathrm{km}$ \\
\hline \multirow[t]{9}{*}{ Preservation } & Transport of culms & 1486,4 kg-km \\
\hline & Water & $172,8 \mathrm{~kg}$ \\
\hline & Transport of water & $1728,0 \mathrm{~kg}-\mathrm{km}$ \\
\hline & Boric acid production & $0,400 \mathrm{~kg}$ \\
\hline & Transport of boric acid & $71,2 \mathrm{~kg}-\mathrm{km}$ \\
\hline & Boric oxide production & $0,4 \mathrm{~kg}$ \\
\hline & Transport of boric oxide & $71,2 \mathrm{~kg}-\mathrm{km}$ \\
\hline & Insecticide production & $0,007 \mathrm{~kg}$ \\
\hline & Transport of insecticide & $1,242 \mathrm{~kg}-\mathrm{km}$ \\
\hline \multirow[t]{7}{*}{ Manufacturing } & $\begin{array}{l}\text { Transport of preserved culms to the } \\
\text { plant }\end{array}$ & $13228,9 \mathrm{~kg}-\mathrm{km}$ \\
\hline & Steel sponges production & $0,180 \mathrm{~kg}$ \\
\hline & Vinyl acetate production & $0,990 \mathrm{~kg}$ \\
\hline & Urea formaldehyde production & $0,990 \mathrm{~kg}$ \\
\hline & Water & $1,000 \mathrm{~kg}$ \\
\hline & Electricity for pressing & $2,798 \mathrm{kWh}$ \\
\hline & Electricity for chopping & $0,187 \mathrm{kWh}$ \\
\hline
\end{tabular}

\section{Results and discussion}

\subsection{Contribution analysis}

The life cycle GHG emissions associated with the functional unit at the manufacturing plant level is $9.3 \mathrm{~kg} \mathrm{CO}_{2}$. Fig. 4 presents the percentage contribution of each process in the system. Processes that account each one for less than $1 \%$ have been grouped as "Rest of processes", which contributes $3.4 \%$ to the carbon footprint of the system.

The production of the glue ingredients, urea formaldehyde and vinyl acetate, are the processes that contribute the most to the carbon footprint of the system 
with 27.6 and $20.1 \%$ respectively. This is, the production of the glue ingredients account for almost half of the carbon footprint associated with the studied system. Transport of canes from the plantation preservation site to the manufacturing plant is also an important contributor with $17.1 \%$ of the total carbon footprint. Electricity for hydraulic pressing accounts for $12.4 \%$ of the carbon footprint. The production of the boric oxide used during the preservation phase accounts for $7.6 \%$ of the total carbon footprint. The production of steel sponges, boric acid, transport of preservation water, transport of culms, and production of insecticide account for less than $3.3 \%$ each.

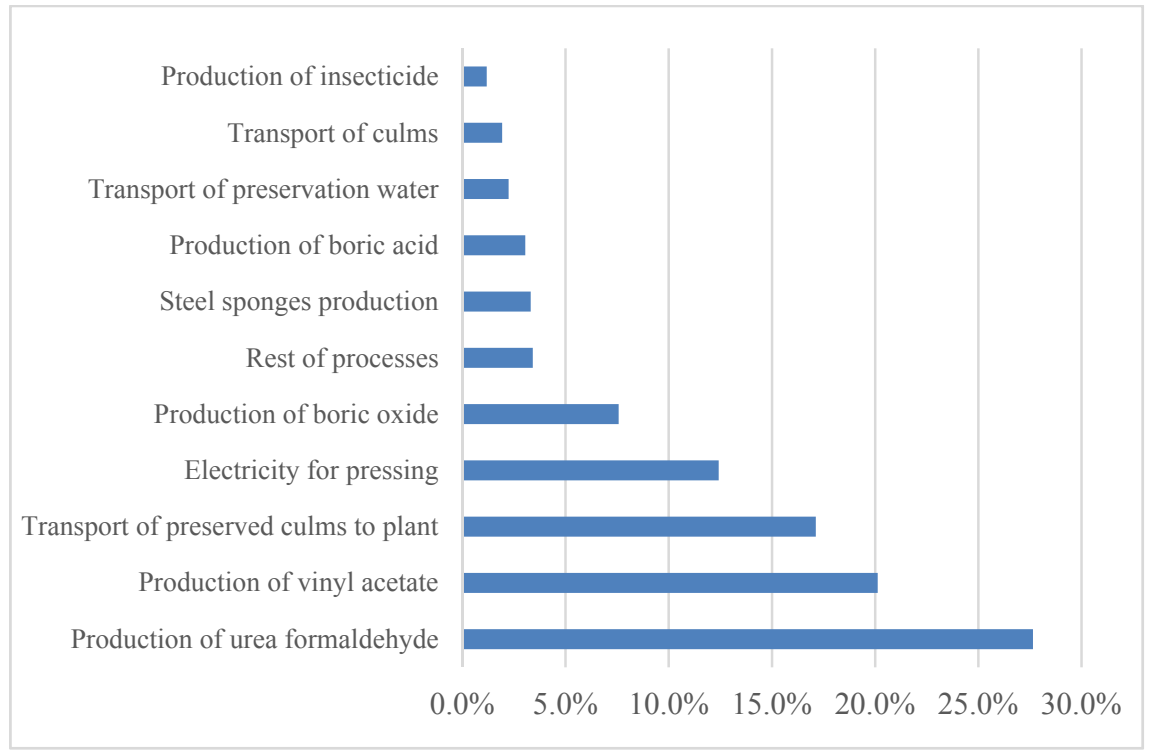

Figure 4: Contribution of processes to the GHG emissions associated with the GAKGPP at the manufacturing plant gate.

The manufacturing of the GAKGPP accounts for $81 \%$, the preservation for $17 \%$ and the agricultural phase for $2 \%$ of the total carbon footprint of the system. The agricultural phase has a minimal contribution since the quantities of agricultural inputs utilized in GAK plantations are not important (Table 1). It should be noted that the amount of agricultural inputs may vary to those used in other sites. Therefore, the low contribution of the agricultural phase is not necessarily a result that can be considered generic for GAK panels.

The main GHG emissions during the preservation phase are the production of chemicals (boric acid and boric oxide), and transport of water and culms. The emissions associated with the production of the chemicals for preservation are the most important in this phase.

The main causes of manufacturing being the most important contributor to the carbon footprint of the system, are the GHG emissions from production of the chemicals used as glue ingredients (urea formaldehyde and vinyl acetate), the 
GHG emissions associated with transport of the canes to the plant, and the GHG emissions associated with the production of electricity for pressing.

Improvement measures should aim at reducing the amount of glue chemicals used or changing the currently used ones for less carbon intensive substances. In this system, the GHG emissions associated with the agricultural phase are not important in comparison to the other stages. It is important to notice that for raw agricultural products, agriculture is normally the most important phase. Taking into account only the agricultural phase, the most important processes are the emissions during production and application of urea. The use of fertilisers is the main contributor to the carbon footprint of the raw agricultural product (nonpreserved GAK canes).

\subsection{Traditional GAK panels vs. GAKGPP}

The GAKGPP are alternatives to the traditional GAK panels, therefore their carbon footprint should be compared in order to provide insights about the climate change perspective to this change. The study presented here is intended at examining the GHG emissions at the manufacturing plant gate, however to perform a comparison of the alternative materials, the durability during the use phase should be considered. Durability of traditional GAK panels is known to be 4.5 years. The life span of a GAKGPP is expected to be between 20 and 30 years, however it may be claimed that it will last between 25 and 40 years. Therefore scenarios for covering 25 to 40 years with traditional GAK panels were developed, taking into account the replacement of GAK panels every 4.5 years. It should be taken into account that 2 canes are needed to manufacture a GAKGPP and only 1 for the traditional panel. Technical and safety features of GAKGPP and traditional GAK are different, and therefore they are not totally functional equivalents, however it is important to have an insight about their comparative Climate friendliness.

Figure 5 illustrates the carbon footprint of the GAKGPP and traditional GAK panels for the considered lifespans scenarios. As expected, the relative Climate perspectives of the GAKGPP, improve when its durability is longer. However, the traditional GAK panels show a lower carbon footprint for all the lifespans scenarios considered. The reason for this is that the most important contributors to the GAKGPP carbon footprint are the preservation and manufacturing phases which are not part of the traditional GAK system. The traditional GAK system only incurs emissions associated with the agricultural phase. In addition, GAKGPP uses the double amount of canes to cover the same area.

\subsection{Further research}

It should be taken into account that the study and comparison performed do not include phases such as, construction, and final disposal of the materials. A complete comparison should include also those life cycle phases. 


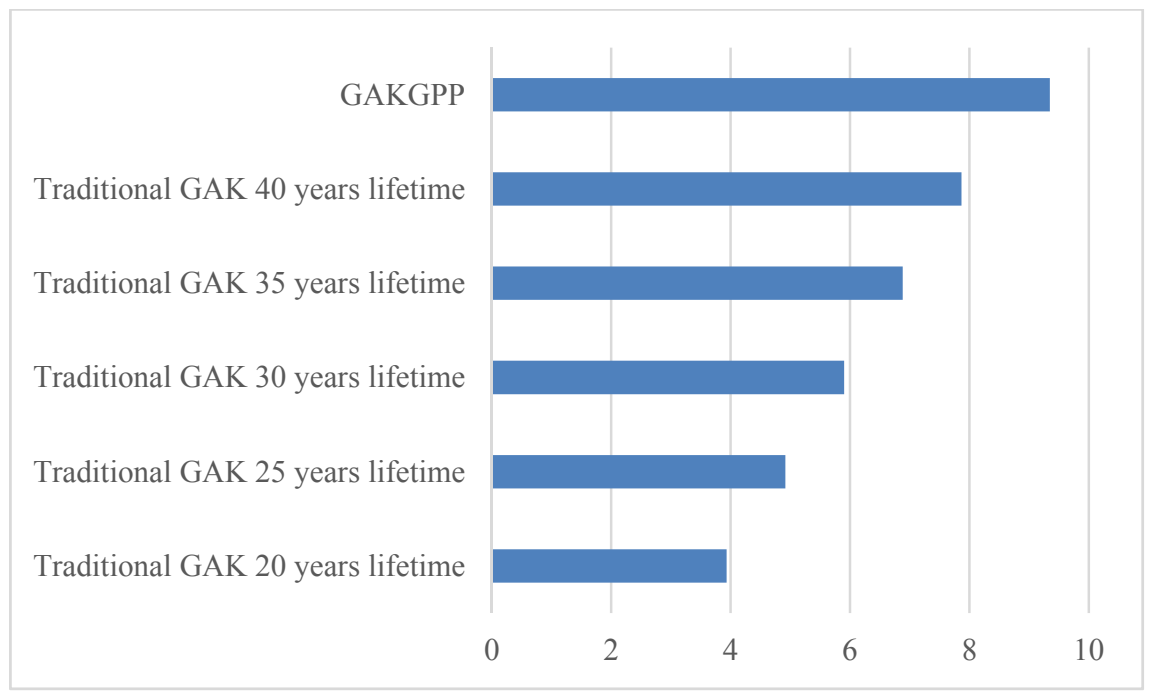

Figure 5: Comparison of carbon footprint $\left(\mathrm{kgCO}_{2}\right)$ of GAKGPP and traditional GAK panels for different GAKGPP lifespan scenarios.

The complete picture of the environmental performance of GAK derived material should be assessed using LCA including other important environmental impact categories such as eutrophication, acidification, photochemical smog formation, toxicity, etc. Only such a study can provide the complete environmental profile of the studied materials.

Furthermore, an approach towards examining the whole building life cycle can provide a deeper insight about the environmental performance of the chosen materials. Yu et al. [11] performed a study to analyse the energy use and the carbon footprint of bamboo structure houses in China. The analysis of the whole building can provide relevant information about the environmental performance of materials and their application. This can be fundamental for whole building energy efficiency and other important environmentally relevant issues during the use phase, which depend on the technical performance of the material choices.

\section{Conclusions}

The life cycle GHG emissions of GAKGPP have been calculated. A GAKGPP is associated with an emission of $9.3 \mathrm{~kg} \mathrm{CO}_{2}$. The main contributors to this result are the production of glue ingredients (urea formaldehyde and vinyl acetate) that are used during the manufacturing stage. The production of those chemicals account for $48 \%$ of the total GHG emissions of the system. GHG emissions associated with the GAKGPP can be reduced by (i) reducing the amount of the current glue ingredients and (ii) using alternative glue ingredients with lower 
carbon footprint than that of the currently used. Transport of canes from the preservation site to the manufacturing plant is also an important contributor. When comparing the carbon footprint of traditional GAK panels to that of GAKGPP, the durability of the GAKGPP is of extreme importance, however the traditional GAK panels have the lowest carbon footprint.

\section{References}

[1] Botero, L., Propagation of Guadua Angustifolia using the Chusquines method. Guayaquil, Ecuador.

[2] CORPEI, Estudio de Mercados Internacionales para Potenciales Productos Ecuatorianos derivados del Bambú. 2005.

[3] Ness, B., Urbel-Piirsalu, E., Anderberg, S., and Olsson, L., Categorising tools for sustainability assessment. Ecological Economics, 60(3), pp. 498508, 2007.

[4] Ortiz, O., Castells, F., and Sonnemann, G., Sustainability in the construction industry: A review of recent developments based on LCA. Construction and Building Materials, 23(1), pp. 28-39, 2009.

[5] Cabeza, L.F., Rincón, L., Vilariño, V., Pérez, G., and Castell, A., Life cycle assessment (LCA) and life cycle energy analysis (LCEA) of buildings and the building sector: A review. Renewable and Sustainable Energy Reviews, 29, pp. 394-416, 2014.

[6] ISO, ISO 14040:2006 Environmental Management - life cycle assessment principles and framework. International Organisation for Standardization, Geneva, 2006.

[7] ISO, ISO 14044:2006 Environmental Management - life cycle assessment principles and framework, International Organisation for Standardization, Geneva, 2006.

[8] BSI, PAS 2050:2011 Specification for the assessment of the life cycle greenhouse gas emissions of goods and services, British Standards Institution, London, 2011.

[9] Vogtländer, J., van der Lugt, P., and Brezet, H., The sustainability of bamboo products for local and Western European applications. LCAs and land-use. Journal of Cleaner Production, 18(13), pp. 1260-1269, 2010.

[10] van der Lugt, P., van den Dobbelsteen, A.A.J.F., and Janssen, J.J.A., An environmental, economic and practical assessment of bamboo as a building material for supporting structures. Construction and Building Materials, 20(9), pp. 648-656, 2006.

[11] Yu, D., Tan, H., and Ruan, Y., A future bamboo-structure residential building prototype in China: Life cycle assessment of energy use and carbon emission. Energy and Buildings, 43(10), pp. 2638-2646, 2011.

[12] BSI, The Guide to PAS 2050:2011 How to carbon footprint your products, identify hotspots and reduce emissions in your supply chain. British Standards Institution, London, 2011.

[13] Google-maps, https://maps.google.com/.

[14] Ecoinvent, www.ecoinvent.org. 
[15] Eggleston, S., Leando, B.d., Miwa, K., Ngara, T., and Tanabe, K., Agriculture, Forestry and Other Land Use. IPCC Guidelines for National Greenhouse Gas Inventories, Intergovernmental Panel on Climate Change, 2006

[16] MEER, MAE, CONELEC, and CENACE, Factor de Emisión del sistema nacional interconectado al año 2012. MEER; MAE; CONELEC; CENACE, Quito, 2012. 